\title{
ARTICLE \\ Impact of Japan's local community power on green tourism
}

\author{
Chenghua $\operatorname{Jin}^{1}$ D $\cdot$ Misuzu Takao ${ }^{2} \cdot$ Masahiro Yabuta $^{2}$
}

Received: 14 April 2021 / Accepted: 8 January 2022 / Published online: 7 February 2022

(c) The Author(s) 2022

\begin{abstract}
The purpose of this study was to analyze the impact of local community power on green tourism (after this, abbreviated as GT). The analytical features were as follows; First, we derived the concept of local community power from "agricultural village activity," "local activity", and "regional support," to describe the degree of cooperation and collaboration among people who use local resources related to agriculture. Second, a theoretical model for the impact of local community power on GT was developed and analyzed. Third, a covariance structure analysis was conducted on the relationships between local community power and GT using data from the 2015 agricultural census. Results of the analysis revealed that local community power has a positive impact on green tourism.
\end{abstract}

Keywords Green tourism · Local community power · SEM analysis

JEL Classification R11 $\cdot \mathrm{Z} 32$

\section{Introduction}

In this paper, we analyze the impact of local community power on green tourism. Agriculture is land-intensive and highly cohesive due to its technical characteristics. For agricultural development, there must be regional cooperation and cooperation

Chenghua Jin

shkin@kanto-gakuen.ac.jp

Misuzu Takao

mtakao441@g.chuo-u.ac.jp

Masahiro Yabuta

yabuta@tamacc.chuo-u.ac.jp

1 Faculty of Economics, Kanto Gakuen University, 200, Fujiagu-cho, Ota, Gunma 373-8515, Japan

2 Faculty of Economics, Chuo University, 742-1, Higashinakano, Hachioji, Tokyo 192-0393, Japan 
in the supply chain, such as the production, distribution, and sales of agricultural products.

As the population of rural areas continues to decline, it is believed that cooperation among local people will increase the welfare of the region. To achieve this, the power of the local community (unity) is necessary. The higher the local community power, the more it will positively affect the implementation of Green Tourism (GT) ${ }^{1}$ policies to revitalize the region.

The structure of this article is as follows. In Sect. 2, we review previous studies. In Sect. 3, we explain the local community power from Ostrom's common pool approach, which concerns the necessity of cooperation and collaboration in rural communities, and clarify the management of local agricultural resources. In Sect. 4, we conducted an empirical analysis, following the Census of the Ministry of Agriculture, Forestry, and Fisheries, and summarized the data analysis. In Sect. 5, based on data from the Agriculture and Forestry Census of 2015, we quantified a measure of the "local community power," which is a latent variable indicating the cohesiveness of the region. Then, we also conducted a field survey on rural areas related to the development of GT from the data. Moreover, we investigate the impact of the "local community power" on GT. GT is one effort to revitalize rural villages. The status of GT is a question item in the Census of 2015. This paper analyzes the relationship between GT initiatives and agricultural village activities using structural equation modeling (SEM) techniques. Finally, in Sect. 6, we overview the conclusions and describe the remaining analysis tasks.

\section{Literature review}

In line with the purpose of this paper, a review of previous studies on local community power and its relevance to sustainable rural development through local community power and GT will be discussed. There are few clear studies on local community power, and previous studies focusing on cohesion and cooperation in rural communities and farming villages in Japan include, for example, Tabayashi (2000) on community activities and sustainable rural development in Japan, Kamijo and Hirota (2006) on local government and community reorganization, and rural communities related to resource management. Communities related to resource management, Odagiri (2013). Other international examples include Kelly et al. (2017) on water management and Rivera and Kapucu (2015) on disaster recovery. Furthermore, Hashizume (2005, 2015) has a qualitative analysis of structural changes in agriculture and rural areas, using agricultural census data on the current status of efforts to revitalize villages and the current status and trends of local resource management. Additionally, there are papers on rural community cooperation on renewable energy supply in the region, such as Rachmawati and Fountain (2020) and Muharam et al (2020). While previous studies have analyzed

\footnotetext{
${ }^{1}$ Green tourism is defined as a stay-type leisure activity where you can enjoy nature, culture, and interaction with people in the agricultural, mountain, and fishing village areas. (source:https://www.pref.tochi gi.lg.jp/g02/noson-chusankan/documents/03.pdf).
} 
the activities of rural residents for their communities (water management, disaster recovery, community revitalization, local resource management, etc.), there has been no analysis of the concept of local community power, which represents the cohesion of local residents through their activities data. Therefore, the significance of the impact of local community power on GT is important. Next, research on GT has focused on prior research on agri-tourism in the EU (OECD 1994) and recent evaluations on the purpose of revitalizing regions and promoting exchanges between urban and rural areas. For example, Ohe (2019) analyzes GT from environmental, economic, and social perspectives and points out that economic efficiency must be improved for sustainable GT. Yabuta (2020) found that the implementation of GT eliminates the economic disparity between urban and rural areas. In addition, Adamov et al. (2020) analyzed a specific region in Europe as a GT study for sustainable rural development by improving the living conditions in rural areas through GT. Galluzzo (2021) conducted a quantitative analysis of the role of GT to rural areas in Romania. In Kazlouski et al. (2020), a model was developed and analyzed in which GT can be sustainable in rural areas. In other words, many studies consider GT from the business perspectives to increase local income or welfare. However, as noted above, there is little research of the reciprocity between the rural community power and GT, which is a preliminary step in the analysis of the impact of GT on local revitalization. Under the hypothesis that local community power, which represents the community's cohesion, is necessary for the successful implementation of GT, local community power is significant for the theoretical and empirical analysis of GT. In this paper, we first create a new variable, local community power, based on the theoretical analysis of the "common pool approach," which Ostrom (1990) and Ostrom et al. (1994) developed. Then a theoretical model clarifies the local community power to influence local revitalizations. Moreover, a quantitative analysis using data from the 2015 Agriculture and Forestry Census examines local community power. Because the covariance structure analysis is a standard method for analyzing the variables simultaneously, this study will use covariance structure analysis to examine them.

\section{Common pool approach}

\subsection{Community resource management and common pool approach}

In daily life, it is not possible to live without cooperation or help among community members. The "agricultural settlements" and "community functions" analyzed in this paper are examples of everyday people's cooperation and collaboration. In economic theory, Ostrom's idea of a third road (capital that is not privately owned or government owned, but, rather, common social capital) has been studied extensively (including Uzawa and Mogi 1994). The common pool approach based on Ostrom (1990), Ostrom et al. (1994) is explained as a basis of this paper. 


\subsection{Theory overview}

There are two theoretical foundations for the analysis in this paper. The first is that it is difficult to make optimal use of local joint resources because of their non-exclusion and competitiveness. Therefore, to make efficient use of joint resources, it is important to define the scope and management rules for organizing and using local resources by stakeholders. Well-known theories like the common pool approach and efficient regional resource management are based on the discussions of Ostrom et al. The common pool approach provides a theoretical basis concerning the effective use of local resources. The second theory is a hypothesis on the effectiveness of specific rural community activities and management. In this scenario, a certain agricultural village uses local resources (common pool resources) for production activities, such as agriculture. The number of agricultural workers is $n$. If the production function $y$ of the related industry of common pool resources has a Cobb-Douglas type function, the profit margin of the region can be written as follows:

$$
\Pi-w n-r R, y=n^{\alpha} R^{\beta} .
$$

Here, $R$ is the input amount of common pool resources, $r$ is the rental cost, and $\mathrm{w}$ is the wage for agriculture. Also, $\alpha, \beta<1$ is assumed. Here the efficiency condition (profit maximization condition) of Eq. (1) is

$$
\frac{\partial y}{\partial R}=\beta n^{\alpha}\left(R^{*}\right)^{\beta-1}=\frac{r}{p} .
$$

The resource input that satisfies Eq. (2) is $R=R^{*}$. On the other hand, the resource input that satisfies the maximum production (zero profit) condition under diminishing returns is

$$
\frac{y}{R}=n^{\alpha}\left(R^{C}\right)^{\beta-1}=\frac{r}{p},
$$

$R=R^{C}$ satisfies that condition. At this time, it is understood that $R^{C}>R^{*}$. This is a typical example of excessive use of common pool resources. To avoid externalities, local communities need to control the use of $R$. Here, to introduce the $\theta$ index indicating the effectiveness of common pool resource management, the controlled resource usage level $R$ is

$$
R=\theta R^{*}+(1-\theta) R^{c}=\left[\theta \beta^{1 /(1-\beta)}+(1-\theta)\right]\left(\frac{p}{r}\right)^{1 /(1-\beta)} n^{\alpha /(1-\beta)} .
$$

In Eq. (4), $\theta=0$ and $R=R^{c}$ when there is no control by the local community power. On the other hand, with effective control $(\theta=1), R=R^{*}$ is considered to be realized. At this time, there is an efficient use of common pool resources. The term $\theta$ in (4) can be a local community cooperation index (referred to as "rural community power"). From (4), it is clear that the adequate resource use of the community can be attained corresponding to $\theta$ itself, meaning that $\theta$ can be interpreted as a local community power. The second term on the right side of Eq. (4) is defined as follows: 


$$
C=\theta \beta^{1 /(1-\beta)}+(1-\theta)=C(\theta), C^{\prime}<0, C(1)=\beta^{\frac{1}{1-\beta}} \leq C(\theta \in(0,1)) \leq C(0)=1 .
$$

With Eq. (5), the supply function y becomes:

$$
y=\left[C(\theta)^{\beta /(1-\beta)} p^{\alpha+\beta}\left(\frac{1}{r}\right)^{\beta}\left(\frac{\alpha}{w}\right)^{\alpha}\right]^{1 /(1-\alpha-\beta)} .
$$

In this connection, the demand function $\mathrm{d}$ for the production goods (or services) related to the common pool resource is assumed to be the form of

$$
d=d(p, E)=\mu p^{-\gamma} E^{\delta}, \gamma, \delta, \mu>0, d_{p}\left\langle 0, d_{E}\right\rangle 0
$$

Here, $E$ is a common pool resource (the input $R$ of the common pool resource is the amount of "good" produced by the resource $E$ ); it is assumed to be constant in the short term. In addition, $\gamma$ representing the price elasticity of demand takes a small value in the case of goods and services that strongly depend on special products and regional characteristics, is larger in other cases. Under the above conditions, short-term market equilibrium is achieved by the balance of Eqs. (6) and (7). The short-term equilibrium price at that time is

$$
p=\left[C(\theta)^{-\beta /(1-\beta)} r^{\beta}\left(\frac{w}{a}\right)^{\alpha} E^{\delta(1-\alpha-\beta)} \mu^{(1-\alpha-\beta)}\right]^{1 / A}, A=\gamma(1-\alpha-\beta)+(\alpha+\beta)>0 .
$$

Next, we consider the social welfare function of the local community power. The industry related to the common pool resources in the region receives the profit $\Pi$ in Eq. (1), the total income $W$ of the community is the sum of profit $\Pi$, the labor wage $w n$, and the resource use payment $r R$,

$$
W \prod+w n+r R=p y .
$$

Therefore, substituting Eqs. (6) and (8) into (9), we have:

$A \log W \beta(1-\beta)(\gamma-1) \log C(\theta)+\beta(1-\gamma) \log r+\alpha(1-\gamma) \log \left(\frac{w}{a}\right)+\delta \log E+\log \mu$.

Importantly, Eq. (10) shows that "the level of welfare in the region (indicated by income) depends on the amount of local resources $E$ and the local community power $\theta$, in addition to several economic variables". ${ }^{2}$ In Eq. (10), $\frac{\partial \log W}{\partial \theta}>0, \frac{\partial \log W}{\partial \mu}>0, \frac{\partial \log W}{\partial E}>0$ holds. From this, it can be seen that improvement in local community power, an increase in the amount of local common pool resources used, and an increase in demand for local products all increase the level of welfare in the region. In other words, the results of the theoretical analysis show that the stronger the local community power, the more positive the effect on

\footnotetext{
${ }^{2}$ For the theory of the common pool approach, see Imaizumi et al. (2004), Yabuta (2008), Jin and yabuta (2019).
} 
local income, or local welfare. On the other hand, GT is a measure to improve the farm's income (in the paper, we think of farm income to express the welfare). GT has been implemented in Japan for more than 25 years, but various issues remain. During this period, while Japan's economic development continued, the scale of cultivation was shrinking in rural areas, the rural population was declining, and the population was aging. Successful implementation of GT in rural areas may lead to regional success, but the success of the region is due to the growing "local community power." GT, including other local policies such as sixth industrialization, ${ }^{3}$ ecotourism, etc. The paper shows that regional policies such as GT will be effectively implemented by enforcing the local community power. Using this result, in Chapter 4 below, we feature the Structural Equation Modeling to clarify the effect of local community power on green tourism, which is also being implemented to revitalize the region. There is a method of quantitative analysis as an analysis method, but due to the extraction of latent variables such as local community power, this study will use the Structural Equation Modeling method that can extract latent variables and perform correlation analysis at the same time.

\section{Data}

Table 1 shows the breakdown of the data used in this paper, and the Table 2 shows the numerical data by prefectures. In the table, the target area classification is agricultural villages by prefectures (For example, Tokyo, Hokkaido, Osaka, and Gunma, etc.). The principal component score is calculated from the status of seven activities in the agricultural village, defined as "agricultural settlement activity." In comparison, "local activity" is calculated from the four "regional activities," including agricultural villages, using the same method. In addition, the "regional support level" is calculated taking into account inter-subsidiary cooperation with NPOs, schools and companies, and government subsidies. These three indicators ("agricultural settlement activity," "local activity," and "regional support") are considered as observation variables, and "local community power" is considered as a latent variable.

In previous studies, the clear concept of local community power has not been clarified, especially regarding the local community power that is necessary for the sustainable development of rural areas. This conceptualization of local community power is a unique feature of the paper. Therefore, considering the current situation of rural areas in Japan, on the whole, the midst of the decline of rural areas, what explains the local community power of these areas is not just activities for agricultural production, but also activities for the community and activities by NPOs including local people, farmers and people outside. Furthermore, active support from the local government to prevent the decline of the community would

\footnotetext{
3 Comprehensive and integrated promotion of agriculture, forestry, and fisheries as primary industries, manufacturing as secondary industries, and retail business and other businesses as tertiary industries. This is an initiative to create new added value by utilizing the rich local resources of agricultural, mountain and fishing villages (see Ministry of Agriculture, Forestry and Fisheries Website.).
} 


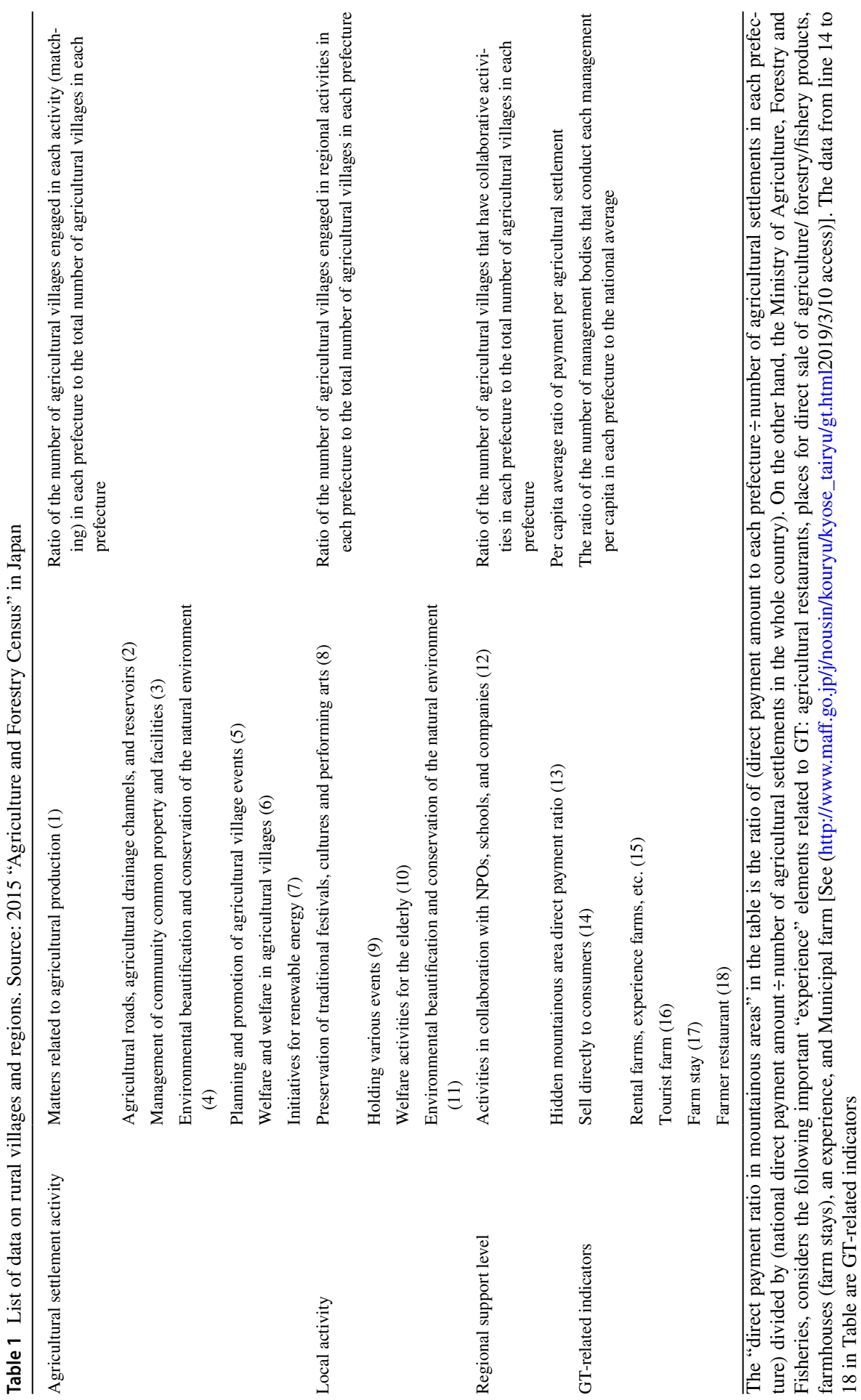




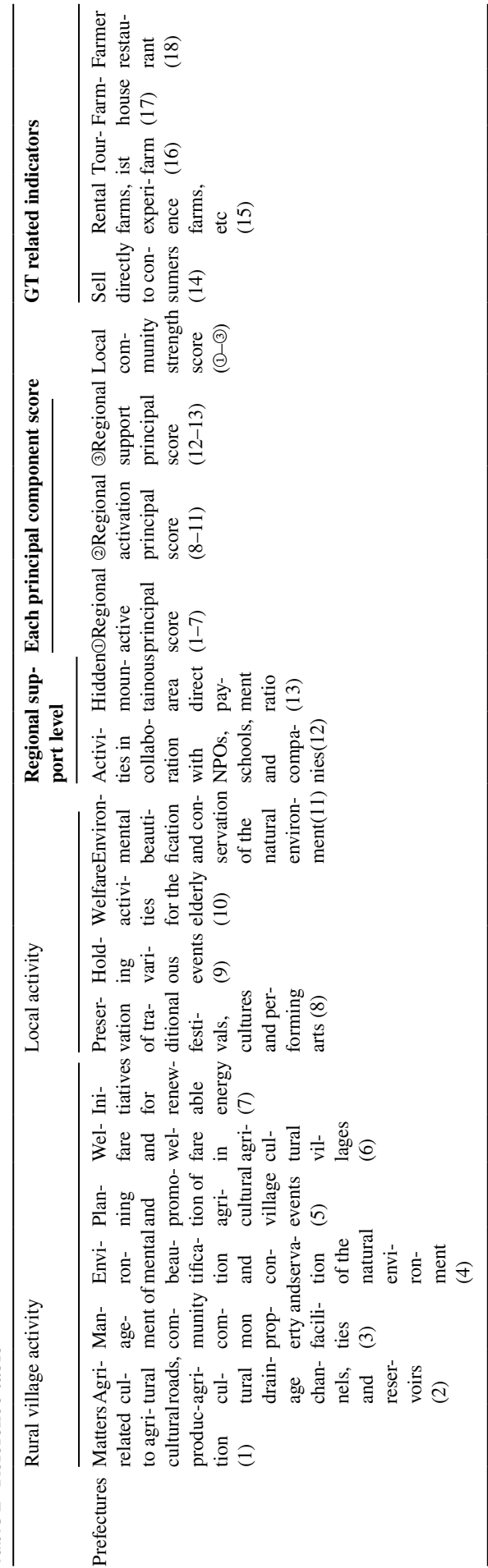

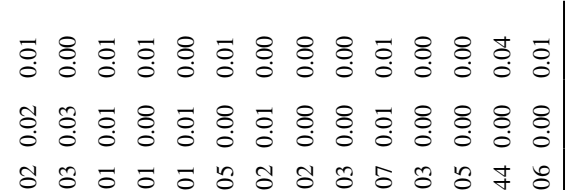
䒓

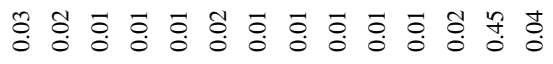

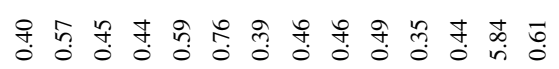
स. సี สู

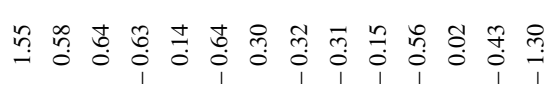

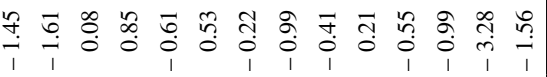
孛 ๖

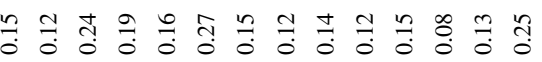

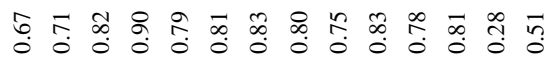
भั

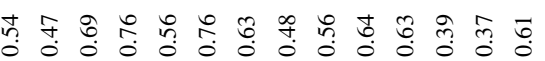

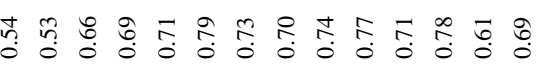
迥

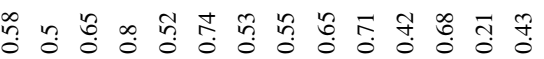

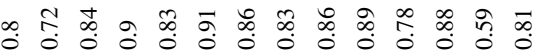

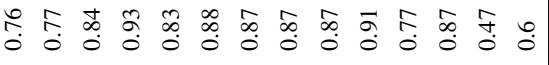

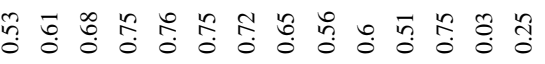
กิ

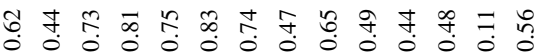






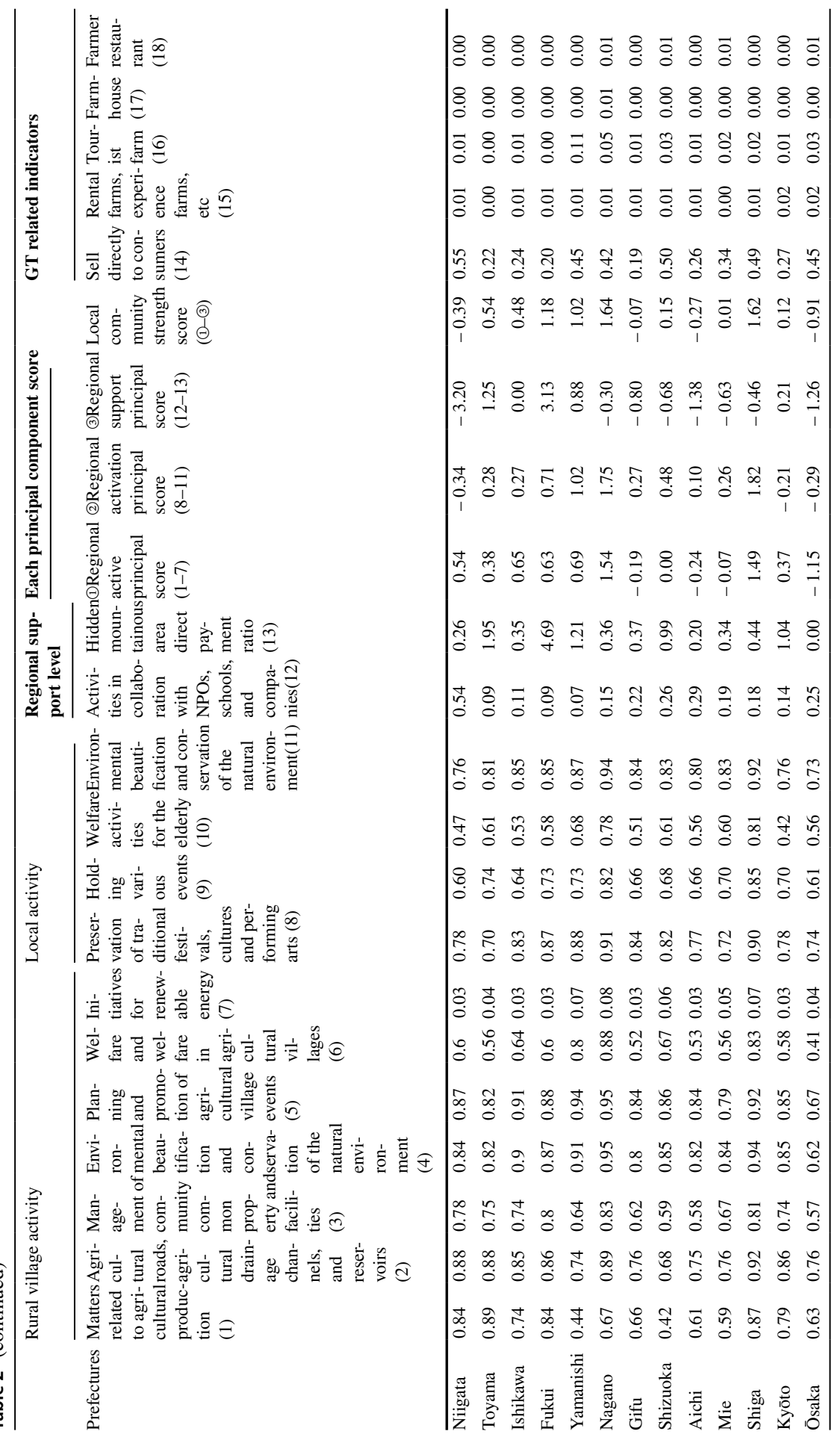




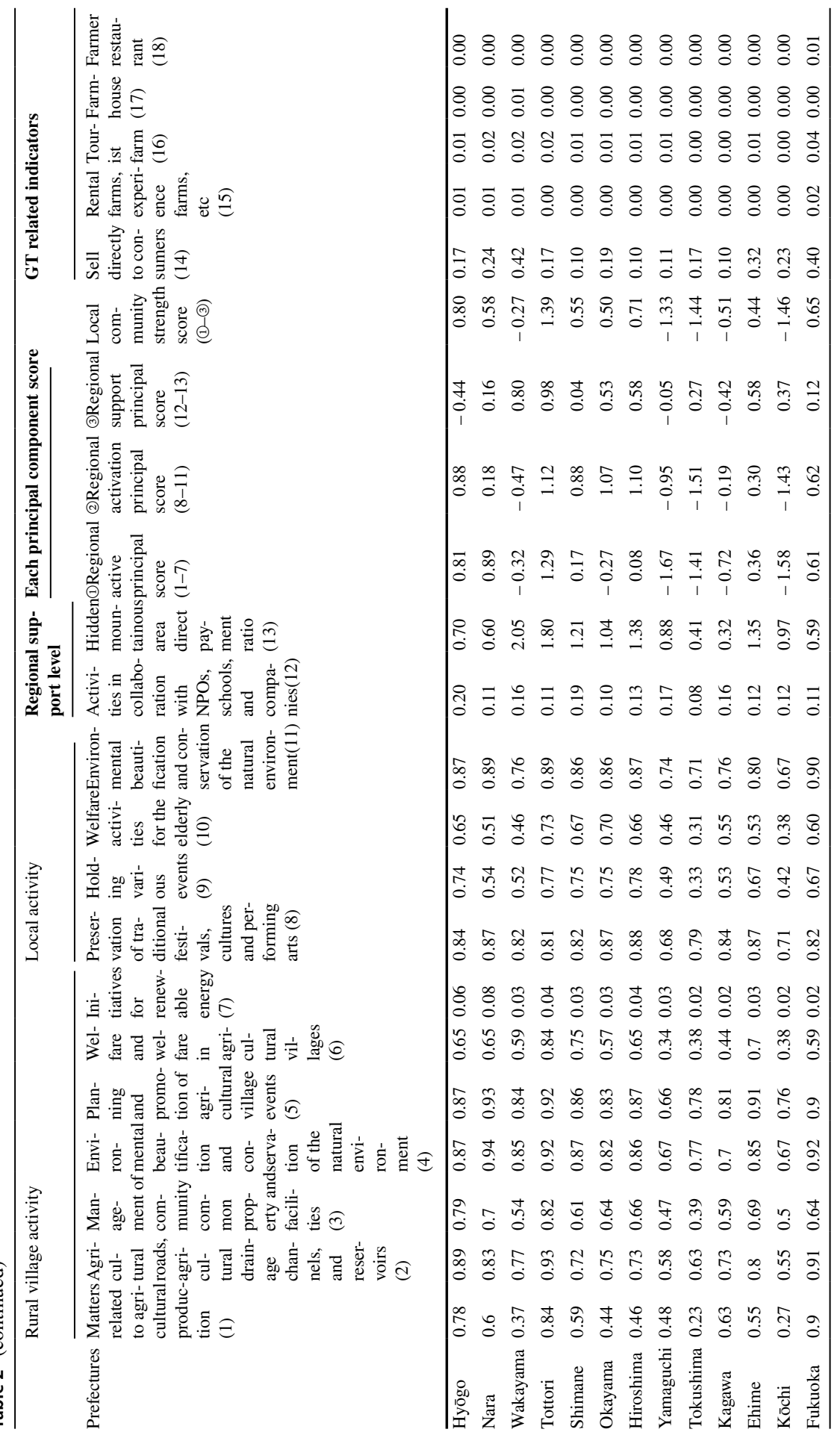




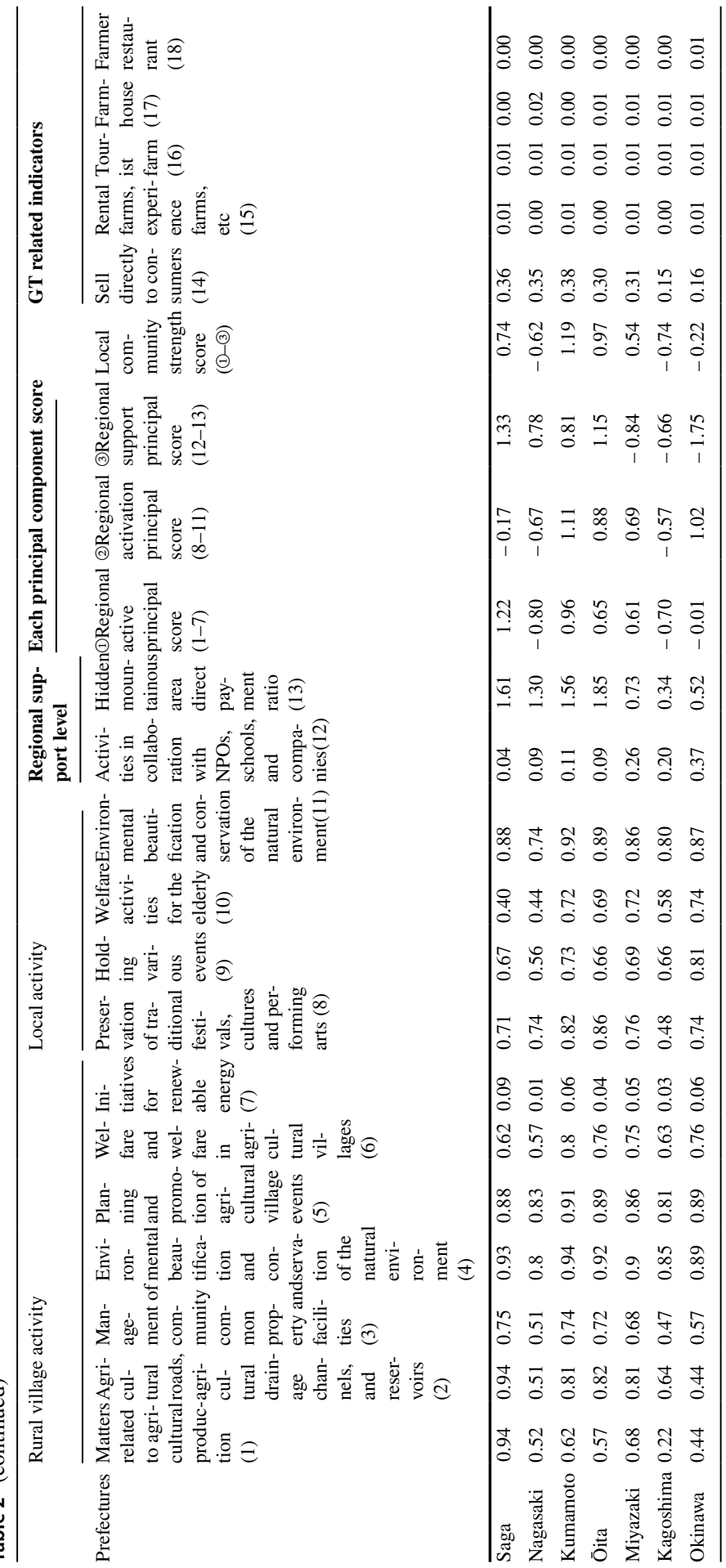


also represent the current local community power of Japanese rural areas. For these reasons, it is thought that the local community power of the current Japanese rural areas is better explained by the multiple levels of community power, consisting of the level of agricultural community activity, the level of community activity, and the level of the community support. Next, concerning GT, the number of management entities that manage businesses such as direct sales to consumers, rental farms/experience farms, tourism farms, farmhouses (farm stays), and farm restaurants make up a GT-related indicator, shown as a ratio to population. Using these data, an analysis by SEM is performed.

\section{Data analysis}

\subsection{Analysis methods and hypotheses}

With the rapid economic growth in Japan since the 1960s, the population became concentrated in urban areas. Concurrently, the working population decreased in rural areas and there was a problem of depopulation between urban areas and rural areas. In addition, the average age of workers in the agricultural and mountain villages was rising and the economy of these regions was declining. The Ministry of Agriculture, Forestry and Fisheries stated that "the supply of food and other agricultural products generated by agricultural production activities in rural areas such as national land conservation, water resources cultivation, natural environment conservation, good landscape formation, cultural traditions, etc. is called multi-functionality of agriculture and rural areas". ${ }^{4}$ To maintain and demonstrate these functions, it is necessary to maintain and manage rural communities in a sustainable manner. In this paper, based on this idea, we perform quantitative analysis according to the following steps.

【STEP1】Regarding agricultural villages, derive "local activity," "agricultural settlement activity," and "regional support" by principal component analysis. Then, determine "community power" as "comprehensive power" using the three derived variables.

【STEP2】 Clarify the correlation between "local community power" and the GT initiative indicators.

【STEP3】 Based on Step 1 and Step 2, perform SEM analysis, clarify the relationship between the whole variables, and analyze the contents.

The two main hypotheses are as follows.

4 "Food, Agriculture and Rural Basic Law" (1999 Law No. 106). 
H1: There is a relationship between local community power and the GT initiative index.

$\mathrm{H}$ 2: Local community power is related to agricultural settlement activity, local activity, and regional support.

\subsection{Analysis results}

\subsubsection{Derivation of "local community power"}

First, the variables related to the "agricultural settlement activity" of agricultural villages are derived by principal component analysis. Data on the number of agricultural villages came from the agenda for the discussion of the No. 7 Rural and Mountain Village Area Survey Report, Part 2 of the Agricultural and Forestry Census Data. Engagement means that decision-making on matters related to local communities or agricultural production is based in the community; this variable represents the degree of activity in the community. Calculating the proportion of agricultural villages that held discussions on each agenda, and performing principal component analysis on the seven variables shown in Table 1, the principal component was derived.

Similarly, variables related to the "local activity" of agricultural villages were derived by principal component analysis. We used activity data shown in the activation of the No. 7 Rural and Mountain Village Area Survey Report, Part 2 of the Agricultural and Forestry Census Data. In the census, activity for revitalization refers to "activity that is mainly led by local residents, and that has been discussed and approved in the region." to revitalize rural villages in anticipation of the future of agricultural villages. In the census data, the following eight items are investigated to show the existence of revitalization activities: "preservation of traditional festivals, cultures and performing arts," "holding of various events," "welfare activities for the elderly," "environmental beautification and conservation of the natural environment," "GT initiatives," efforts to convert to the so-called sixth industrialization," "efforts to promote settlement," and "renewable energy initiatives." However, regarding the four variables of "GT initiatives," "efforts toward the sixth industrialization," "efforts to promote settlement," and "renewable energy initiatives," activities have been shallow since the introduction of the initiatives. Since the number of villages is small, and because they were not included in the questions in the Agricultural and Forestry Census Survey until 2010, the four variables of local activity, numbered $8-11$ in Table 1 , were used to perform principal component analysis. Only the first principal component is derived, and this is defined as "local activity."

For "regional support," we extracted the principal components from the variables of national efforts and NPO efforts. Specifically, as a support for agricultural villages from the country, the amount paid per agricultural village is calculated from the amount paid to each prefecture in the special payment system for mountainous areas in 2015 to calculate a national average ratio. Only the first principal component, "regional support level," is derived. 
As we mentioned earlier, we derived the local community power following the procedures of 【STEP1】. In other words, using the principal components, we derive "community power," which is a comprehensive index. The first principal component was extracted from the three variables of "agricultural settlement activity," "local activity," and "regional support." "local community power" was then derived (see Table 2). As far as the PCA analysis is concerned, the result is only referring to the first PCA, so that we do not use the second PCA.

\subsubsection{GT initiatives}

For GT measures, data on the "number of management bodies by business type engaged in agricultural production-related business" found in Volume 5 of the Agricultural and Forestry Management Organization Survey Report-Extraction Aggregation is used. Divided by the population of the prefectures (unit: 1000 people), GT density was obtained. The items "number of business units by type that conduct agricultural production-related business," "rental farms/experience farms, etc.," "tourism farms," "farm inns," and "farm restaurants" are characteristics that indicate GT activities. Therefore, these four variables were used in the SEM analysis (see Table 2).

\subsubsection{Correlation between local community power and GT initiative indicators}

Table 3 shows the correlation coefficient between local community power and each variable of the GT initiative index. When a normality test was performed, the null hypothesis that "this variable has a normal distribution" was rejected (Table 4), and Spearman's correlation coefficient was calculated.

\subsubsection{Data analysis by SEM}

When the correlation coefficient was calculated in Sect. 4.2.3, there was a certain degree of correlation between the local community power and each GT indicator and no variable had a negative correlation with local community power. Based on this, then examined the causal relationship of improving GT efforts and improving local community power using covariance structure analysis.

For H1, we conducted a covariance structure analysis to see the relationship between "local community power" and "GT initiative indicators." Table 5 shows the descriptive statistics of the observed variables.

Here, regarding the item "number of management entities by business type of management bodies engaged in agricultural production-related business," there are three models: the multiple indicators and multiple causes (MIMIC) model, the partial least squares (PLS) model, and the multiple indicator model. After analysis, a model with high fitness was adopted. According to Toyoda (2007), in the MIMIC model (Fig. 1), a constituent concept is defined by a plurality of observation indices, and the constituent concept causes a plurality of observed variables. The PLS model (Fig. 2) examines the strength of the influence of a new variable that is purely indexed by multiple observed variables on the construct that is assumed behind 


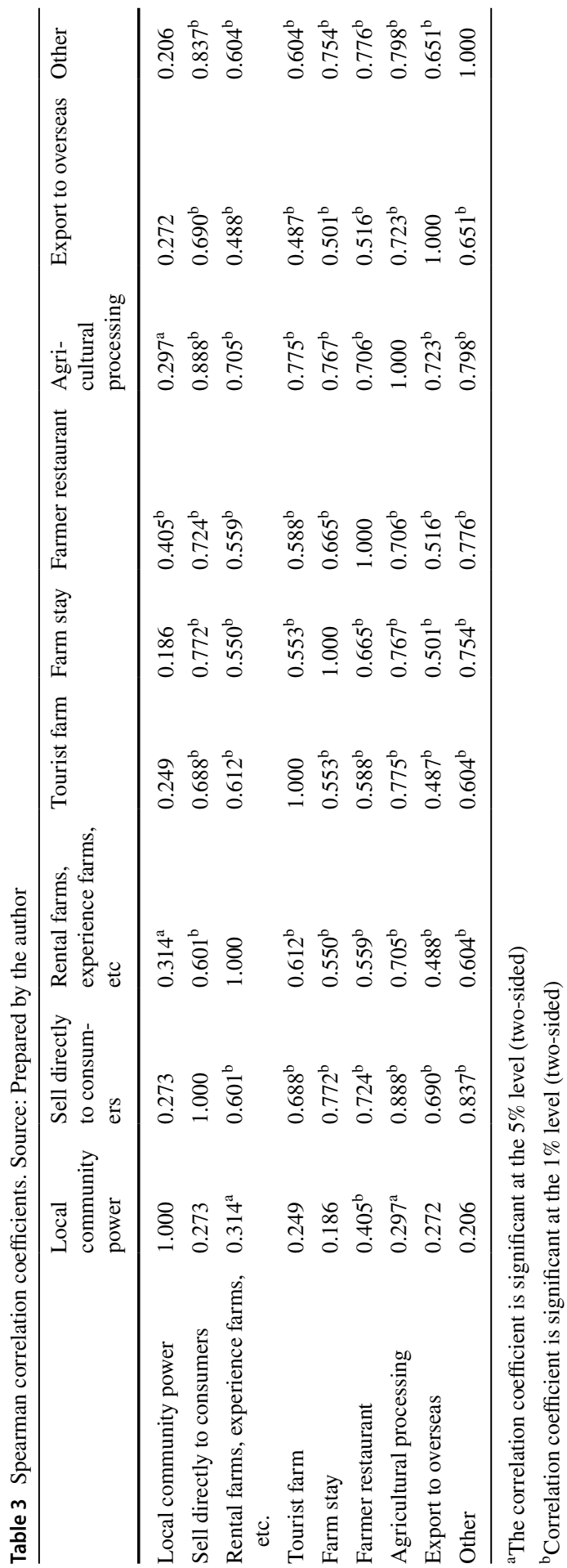


Table 4 Shapiro-Wilk normality test. Source: Prepared by the author

\begin{tabular}{llll}
\hline & Statistics & Degree of freedom & Significance \\
\hline Sell directly to consumers & 0.9094825 & 47 & 0.0014662 \\
Rental farms, experience farms, etc. & 0.8691946 & 47 & $8.597 \mathrm{E}-05$ \\
Tourist farm & 0.5893152 & 47 & $3.045 \mathrm{E}-10$ \\
Farm stay & 0.7239626 & 47 & $4.548 \mathrm{E}-08$ \\
Farmer restaurant & 0.922558 & 47 & 0.0041059 \\
Agricultural processing & 0.8795315 & 47 & 0.0001704 \\
Export to overseas & 0.773466 & 47 & $4.24 \mathrm{E}-07$ \\
Other & 0.9023641 & 47 & 0.0008575 \\
\hline
\end{tabular}

Table 5 Descriptive statistics. Source: Prepared by the author

\begin{tabular}{llcl}
\hline & Frequency & Average value & Standard deviation \\
\hline $\begin{array}{l}\text { Rental farms, } \\
\text { experience } \\
\text { farms, etc. }\end{array}$ & 47 & 0.013362 & 0.009419 \\
Tourist farm & 47 & 0.030426 & 0.036461 \\
Farm stay & 47 & 0.008021 & 0.011257 \\
Farmer restaurant & 47 & 0.006447 & 0.004471 \\
Rural village & 47 & 0.02202 & 1.011029 \\
support & 47 & $-3.6 \mathrm{E}-16$ & 1 \\
Region & 47 & -0.04155 & 0.997201 \\
\hline
\end{tabular}

other multiple observed variables. The multi-index model (Fig. 3) is a model that assumes an explanatory relationship between constituent concepts. After considering the three models, (Figs. 2, 3, and 4), the multiple index model was adopted. The suitability of each model is shown in Table 6. The first version of the MIMIC model has the smallest Akaike's information criterion (AIC); however, in this model, the path coefficient from local activity to local community power is negative. Since that does not reflect reality, the analysis was performed using the second version of the multi-index model with the lowest AIC (Fig. 4). If the comparative fit index (CFI) is 0.9 or more and the root mean square error of approximation (RAMSEA) is 0.05 or less the model is a good fit and it is considered to have a certain level of explanatory power.

Table 7 shows the standardization coefficients for each path.

Next, a principal component analysis was performed for $\mathrm{H} 2$ to derive the "local community power." Table 8 shows the commonality of "agricultural settlement activity", "local activity," and "regional support," which are related to local community power.

In the principal component analysis, "agricultural settlement activity" and "local activity" have a high commonality: $87 \%$ are explained by "local community power." In contrast, about $8 \%$ of the distribution of "regional support" is explained by "local 


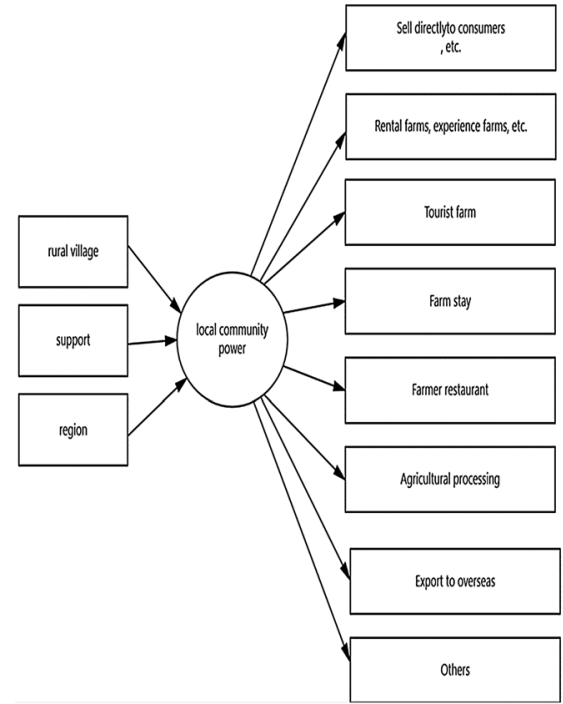

MIMIC1



MIMIC2

Source: Prepared by the author.

Fig. 1 Relationship between "local community power" and "GT initiative indicators" based on the MIMIC model. Source: Prepared by the author

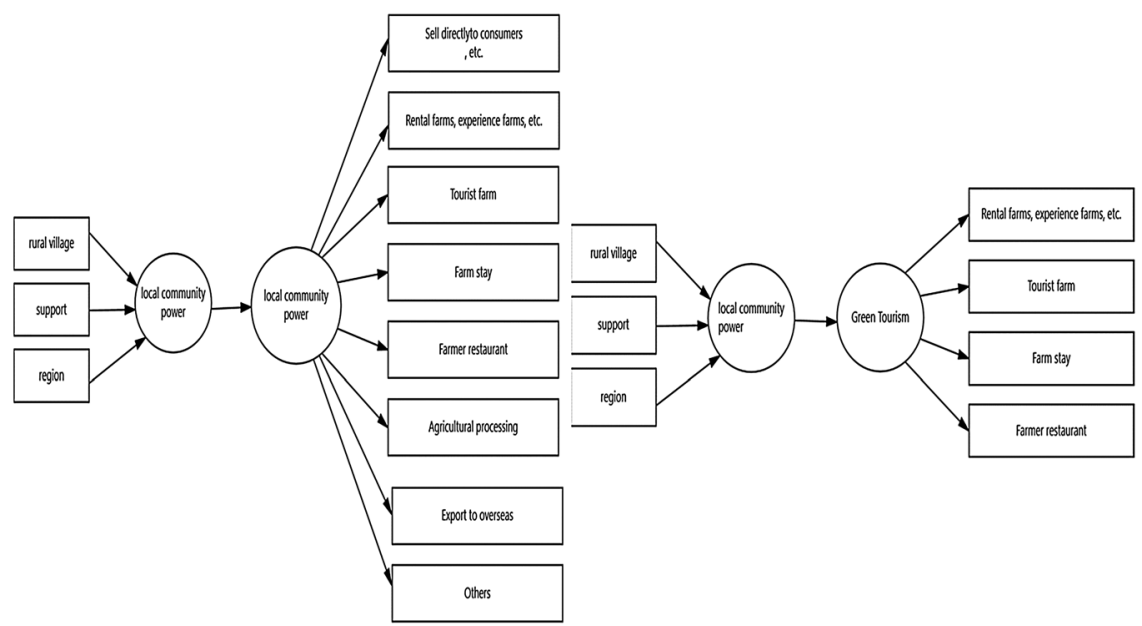

\section{PLS1}

PLS2

Source: Prepared by the author.

Fig. 2 Relationship between "local community power" and "GT initiative indicators" according to the PLS model. Source: Prepared by the author 


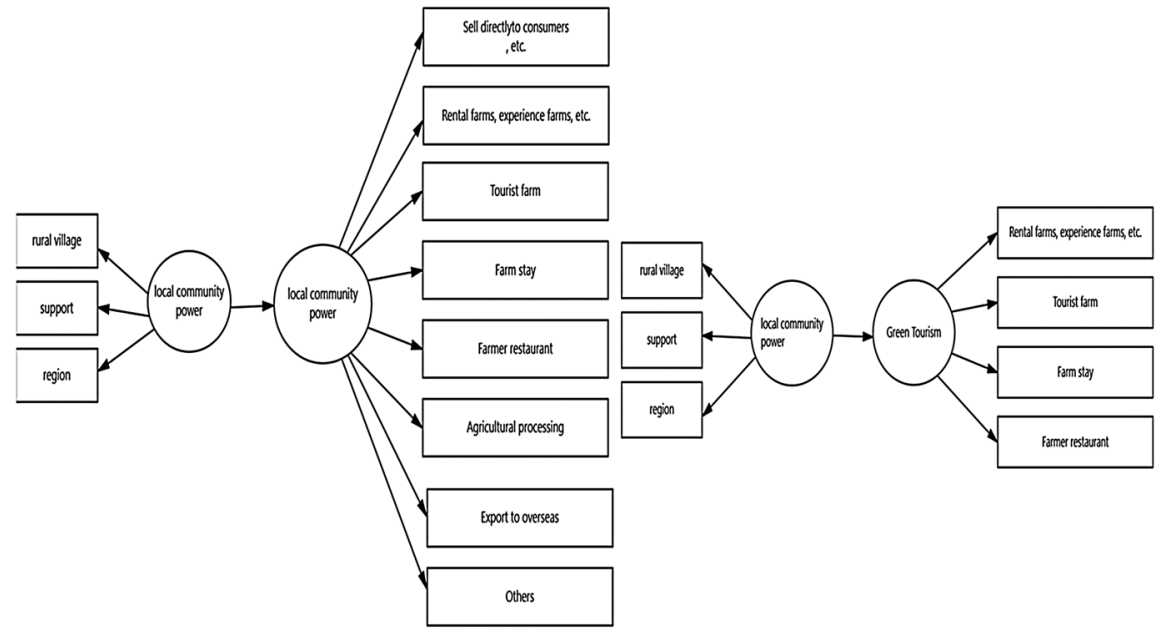

Multiple indicators 1

Multiple Indicators 2

Source: Prepared by the author.

Fig. 3 Relationship between "local community power" and "GT initiative indicators" using a multiple indicator model. Source: Prepared by the author

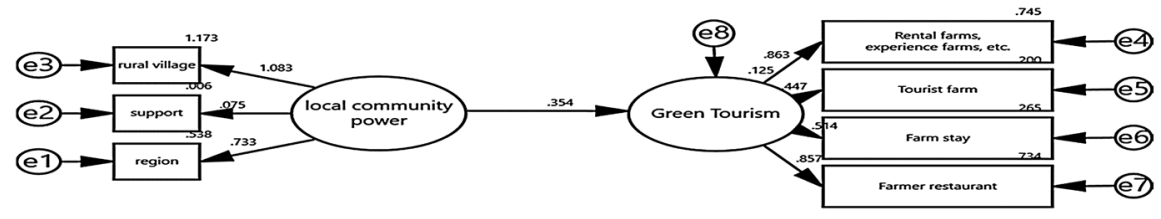

Source: Prepared by the author.

Fig. 4 Multiple index model and standardized path coefficient. Source: Prepared by the author

Table 6 Model comparison. Source: Prepared by the author

\begin{tabular}{lllllc}
\hline & $\chi^{2}$ & $\chi^{2} / d$ & CFI & RMSEA & AIC \\
\hline MIMIC model 1 & 67.51 & 1.647 & 0.912 & 0.119 & 117.51 \\
MIMIC model 2 & 14.758 & 1.342 & 0.965 & 0.086 & 48.758 \\
PLS model 1 & 67.51 & 1.647 & 0.912 & 0.119 & 139.51 \\
PLS model 2 & 65.189 & 4.656 & 0.52 & 0.282 & 107.189 \\
Multiple indicator model 1 & 69.575 & 1.618 & 0.912 & 0.116 & 137.575 \\
Multiple indicator model 2 & 18.282 & 1.406 & 0.951 & 0.094 & 62.282 \\
\hline
\end{tabular}

community power" which is composed of variables related to national support and NPO efforts. Regional power is different from local community power. 
Table 7 Standardization factors. Source: Prepared by the author

\begin{tabular}{llll}
\hline Parameters & & & Estimated value \\
\hline GT Initiative Indicator & $\leftarrow$ & Local community power & $0.354^{* *}$ \\
$\begin{array}{l}\text { Rental farms, experience farms, } \\
\quad \text { etc. }\end{array}$ & $\leftarrow$ & GT Initiative Indicator & 0.863 \\
Tourist farm & $\leftarrow$ & GT Initiative Indicator & $0.447^{* * *}$ \\
Farm stay & $\leftarrow$ & GT Initiative Indicator & $0.514^{* * *}$ \\
Farmer restaurant & $\leftarrow$ & GT Initiative Indicator & $0.857^{* * *}$ \\
Rural village & $\leftarrow$ & Local community power & $1.083^{*}$ \\
Support & $\leftarrow$ & Local community power & 0.075 \\
Region & $\leftarrow$ & Local community power & $0.733^{* *}$ \\
\hline
\end{tabular}

$* \mathrm{p}<0.1, * * \mathrm{p}<0.05, * * * \mathrm{p}<0.01$

Table 8 Principal component analysis on "local community power". Source: Prepared by the author

\begin{tabular}{llc}
\hline Commonality & & \\
\hline & Initial & After factor extraction \\
\hline Rural village activity & 1 & 0.872257839 \\
Local activity & 1 & 0.879278932 \\
Regional support level & 1 & 0.080422147 \\
\hline Component matrix & & Component \\
\hline & & 1 \\
\hline Rural village activity & & 0.93394745 \\
Local activity & & 0.937698743
\end{tabular}

Factor extraction method: principal component analysis

\section{Conclusions and further remarks}

In this paper, we focused on local community power and green tourism, and examined the impact of local community power on green tourism using the 2015 Agriculture and Forestry Census data. Then, we found the following conclusions: (i), as far as $\mathrm{H} 1$ is concerned, local community power influenced the GT initiative index positively, and (ii), as far as $\mathrm{H} 2$ is concerned, we found that local community power is related to agricultural settlement activity, local activity, and regional support. In terms of policy, to expand GT initiatives, it is important to promote local community power. Local community power is strengthened through cooperative activities between rural villages and local residents. It is important to build a foundation for more activities for GT socializing and regional revitalization. 
Currently, rural settlements are declining in Japanese rural areas. The government tries to implement various policies to revitalize rural areas, one of which is the promotion of GT. However, there are various problems in implementing GT. This study clarified that the increase in the local community power has a positive effect on GT. Therefore, efforts should be made to increase the power of the rural community to popularize and succeed in GT. For that purpose, it is necessary to raise the degree of agricultural activity, encourage active participation in local activities, and realize active participation and cooperation of the government and residents.

There is some remaining analysis. This paper tried to define the local community power based on local collaboration and cooperation activities. Since the data used were prefecture-based and single-year Agriculture and forestry Census Data of 2015, there are some further analyses to be extended and improved as follows: First, doing a comparative analysis using data on rural communities (agricultural settlements) on a municipal basis would help specific communities; Second, it would be valuable to create a database using other data sources, like a questionnaire survey for one specific rural village. In addition, conducting a specific empirical study on the impact (economic and employment) of the measures to promote and develop GT in each rural village would be beneficial. Moreover, third, examining panel data of changes in the local community power of rural villages over time would offer helpful insight.

Acknowledgements This work was supported by JSPS KAKENHI Grant Numbers JP20K200443, JP21K20129.

Open Access This article is licensed under a Creative Commons Attribution 4.0 International License, which permits use, sharing, adaptation, distribution and reproduction in any medium or format, as long as you give appropriate credit to the original author(s) and the source, provide a link to the Creative Commons licence, and indicate if changes were made. The images or other third party material in this article are included in the article's Creative Commons licence, unless indicated otherwise in a credit line to the material. If material is not included in the article's Creative Commons licence and your intended use is not permitted by statutory regulation or exceeds the permitted use, you will need to obtain permission directly from the copyright holder. To view a copy of this licence, visit http://creativecommons.org/licen ses/by/4.0/.

\section{References}

Adamov T, Ciolac R, Iancu T, Brad I, Peț E, Popescu G, Șmuleac L (2020) Sustainability of agritourism activity. Initiatives and challenges in Romanian mountain rural regions. Sustainability 12(6):2502

Galluzzo N (2021) A quantitative analysis on Romanian rural areas, agritourism and the impacts of European Union's financial subsidies. J Rural Stud 82:458-467

Hashizume N (2005) New movements of agricultural structure and rural structure: analysis of the 2005 agricultural census. J Agric Policy Res 14:1-36 (in Japanese)

Hashizume N (2015) Functions of rural communities weakened by depopulation and aging: dynamic statistical analysis and estimation of future of rural communities. Rural Issues Assoc Japan 47(1):1424 (in Japanese)

Imaizumi H, Yabuta M, Ida T, Ichikawa Y, Nibu S (2004) Common-pool resources and local community networking: a study of the Onga River Basin. Keizaigaku Ronshu 27(3):9-28 
Jin C, Yabuta M (2019) Rural villages and optimal management of local resources: theoretical study. Keizaigaku Ronsan the J Econ 60(1):297-308 (in Japanese)

Kamijo K, Hirota J (2006) Method of support for community reorganization by municipalities-case study of Kuzumaki town in Iwate prefecture. Trans Rural Plan 25:11-316 (in Japanese)

Kazlouski V, Ganski U, Platonenka A, Vitun S, Sabalenka I (2020) Sustainable development modeling of agritourism clusters. Manag Theory Stud Rural Bus Infrastruct Dev 42(2):118-127

Kelly E, Lee K, Kristen SKF, CronkBehnkeKlugBartram RTNKJ (2017) "The role of social capital and sense of ownership in rural community-managed water systems: qualitative evidence from Ghana Kenya, and Zambia. J Rural Stud 56:156-166

Muharam A, Ahmad S, Hattori R (2020) Scaling-factor and design guidelines for shielded-capacitive power transfer. Energies 13(16):4240

Odagiri T (2013) Rural innovation theory and supporters for rural regeneration. J Rural Plan 32(3):384387 (in Japanese)

Ohe Y (2019) Overcoming challenges toward sustainable rural tourism: a perspective of communitybased tourism. Assoc Rural Plan 38(1):10-14 (in Japanese)

Organisation For Economic Co-operation and Development (1994) Tourism strategies and rural development. https://www.oecd.org/cfe/tourism/2755218.pdf. Accessed 16 Dec 2021

Ostrom E (1990) Governing the commons: the evolution of institutions for collective action. Cambridge University Press, New York

Ostrom E, Gardner R, Walker J (1994) Rules, games, and common-pool resources. University of Michigan Press

Rachmawati E, Fountain J (2020) Role of external stakeholders in tourism development and community empowerment. Int J Appl Sci Tour Events 4(1):25-36

Rivera FI, Kapucu N (2015) Resilience. In: Rivera FI, Kapucu N (eds) Disaster vulnerability, hazards and resilience. Springer, pp 69-81

Tabayashi A (2000) Role of community activities in sustaining rural areas : a case of a rice-growing village on the Kurobe Alluvial Fan in Central Japan. Tsukuba Stud Human Geogr 24:29-54 (in Japanese)

Toyoda H (2007) Covariance structure analysis [Amos]—-structural equation modeling. Tokyo-Tosho (in Japanese)

Uzawa H, Mogi A (1994) Social common capital. University of Tokyo Press (in Japanese)

Yabuta M (2008) Ecotourism development and management of common pool resources: a study of japanese rural communities. Discussion Paper Series No.101.

Yabuta M (2020) Sustainable tourism development and green tourism policy. Annu Inst Econ Res Chuo Univ 52:159-171 (in Japanese)

Publisher's Note Springer Nature remains neutral with regard to jurisdictional claims in published maps and institutional affiliations. 